\title{
Research on the measurement of an independent and controllable high-end equipment manufacturing industry
}

\author{
Yunqing Chen", and Ping Wang \\ Jiangsu University of Science and Technology, Zhenjiang, Jiangsu212003, China
}

\begin{abstract}
Keywords: offshore equipment manufacturing industry, ability of independence and controllability, measurement.

Abstract. Against the present background of trade protectionism and antiglobalization, an independent and controllable high-end equipment manufacturing industry has become the focus of attention from all walks of life. Based on industrial safety and some related theories, this paper analyzes the connotation of an independent and controllable high-end equipment manufacturing industry, constructs a measurement index system of it with patent information, and designs a solution by a combination of "Entropy Method + TOPSIS". At the end of the paper, by using the relevant data of global patent database, the offshore equipment manufacturing industry is taken as an example to measure its ability of independence and controllability. The results show that the measurement index data is consistent with the development status of China's offshore equipment manufacturing industry, which verifies the effectiveness of the index system and measurement method.
\end{abstract}

\section{Einleitung}

The outbreak of trade war between China and the United States, especially the Huawei and ZTE events, fully shows that the key core technology in the hands of others will pose a huge threat to industrial security and economic security. General secretary Xi Jinping repeatedly stressed that "we must strive to achieve the independent control of key core technologies, and firmly grasp the initiative and initiative in our own hands". The high-end equipment manufacturing industry has the characteristics of high-tech content and high added value. It is the key to realize the industrial transformation and strategic industrial development in China, and the powerful driving force for the transformation of a big manufacturing country into a powerful manufacturing country. Under the background of the current trend of trade protectionism and anti globalization, developed countries put the core technology of industry in their own R \& D in order to limit the technological development of developing countries, and make themselves in the upstream of the industrial chain by means of "division of labor strategy of R \& D chain" and outsourcing,

\footnotetext{
*Corresponding author: 2507051519@.qq.com
} 
so as to realize monopoly and control of core technology[1].Most of China's high-end equipment manufacturing industry is in the manufacturing link at the end of the industrial chain, with low design level, weak innovation ability and high dependence on key core technologies. Under the current world political and economic situation, it is vulnerable to foreign checks and balances, which has a great impact on industrial security and economic security. At present, the research framework of industrial security mainly emphasizes the industrial innovation ability, industrial competitiveness, industrialdevelopment ability, industrial recovery ability and industrial control ability [2-4], But the evaluation system of industrial security is more from the macro level, less from the key core technology level. National leaders have repeatedly stressed the need to strive to achieve independent and controllable key core technologies, and firmly grasp the innovation initiative and development right in their own hands[5].Foreign scholars focus on the research of independent and controllable national defense science and technology industry. Hensel and bellais both emphasize that the enhancement of national defense power and the realization of independent and controllable national defense science and technology industry must focus on enhancing the ability of independent innovation[6, 7].Chinese scholars also pay close attention to the autonomous control ability of military industry group. The autonomous control system of military industry group designed by lanyuqing and others mainly includes three aspects: major engineering system, product technology system and service support system [8], Xuguofeng and others discussed the importance of autonomous control technology from the perspective of safety [9], Xu Xiping combined the characteristics of national defense science and technology industry, based on the relationship of knowledge flow, constructed an independent and controllable analysis framework of national defense science and technology industry [10], Wang Liheng stressed the importance of independent and controllable core technology to the maturity of industrial system [11].

\section{Measurement of self control ability of high end equipment manufacturing industry}

\subsection{Analysis on the connotation of independent controllable ability of high end equipment manufacturing industry}

In the early domestic research on industrial security, he Weida and Li menggang found that foreign investment affected China's industrial security through technology control $[12,13]$, Although some early experts pointed out that with the diffusion and introduction of technology, the technology gap eventually tends to converge [14], However, the high-end equipment manufacturing industry technology innovation needs to invest a lot of time and capital cost. The western countries have accumulated in this field for decades, and have obtained great leading advantages. The connotation of autonomous control mainly includes the following two levels:

(1) From the static point of view, autonomous control is a state. It means that the key core technology of high-end equipment manufacturing industry in a country or region has the ability of risk control, that is, the gap between the strength of the key core technology of the industry and the competitors is so small that it is negligible, and even can maintain the leading advantage in some key core technology fields, that is, the key core technology has a certain degree of risk control.

(2) From a dynamic point of view, autonomous control is a kind of ability. It means that the high-end equipment manufacturing industry of a country or region has continuous innovation ability, can continuously create products with independent intellectual property 
rights, control the core technology, and use endogenous resources and technology to lead the whole industrial chain, so the industrial development has high autonomy.

\subsection{Construction of measurement index system for independent controllable ability of high end equipment manufacturing industry}

Cao Ping found that the essence of the competition between high-tech industries is the competition of intellectual property rights in the empirical study of the influencing factors of high-tech industry security [15], At the same time, some studies show that, compared with the technical indicators measured by economic data, intellectual property rights can more objectively reflect the technological innovation level of industries and enterprises by representing the technological innovation elements and core competitiveness of enterprises [16].

\subsubsection{Autonomy index}

To achieve self-control, first of all, we must have the ability of innovation. If a country (or region) industry does not have the ability of innovation, it will be defeated by competitors or eliminated by the market as time goes on; second, we must have the ability of competition, only strong competition can have a certain degree of control in the industrial chain. Therefore, the autonomy index is mainly designed from two dimensions of innovation ability and competitiveness.

(1) Innovation ability. For the existing evaluation system of industrial innovation capability, R \& D input is one of the important indicators, and Griliches empirically gets the conclusion that there is a significant positive correlation between the number of patent applications and the current R \& D cost [17]. Therefore, the selection index of innovation ability mainly includes the number of new invention patent applications, the number of new patent authorization, and the number of new patent citations.

(2) Competitiveness. The more patents a country has in a specific technology field, the stronger the competitiveness of the country (or region) [18]. And the number of highquality invention patents and the total number of citations can better reflect the strength of the national (or regional) industrial competitiveness. Therefore, the selection index of competitiveness mainly includes the total amount of patent authorization, the total amount of invention patent authorization, the total amount of high-quality invention patents, the total number of citations and so on.

\subsection{Controllability index}

Controllability reflects the gap between key core technologies of a country (or region) industry and developed countries (or regions). The smaller the gap, the stronger the industrial controllability. Therefore, the controllable measure indexes mainly include scale gap, quality gap and benefit gap.

(1) Scale gap. The patent scale of a country in an industry can reflect the technological strength of the country in the industry, and the gap in scale can directly reflect the technological gap between the country and its competitors in some specific fields [19].

(2) Quality gap. In the industrial technology system, high-quality core technology is an important factor affecting the technology gap, and the number of patents cited can objectively reflect the quality of the technology [18].Therefore, the relative number of patent citations, the relative number of patents of the same family and the relative number 
of international patent applications are selected as the measurement indicators of the quality gap [19].

(3) Benefit gap. In the high-end equipment manufacturing industry, technological innovation is to obtain market value. Only when it occupies the high-end position of the industrial chain, can it control the industrial chain. The key core technology with high efficiency can not only drive the economic development of the industry, but also support the technology system of the industry. Therefore, based on the existing research, the relative number of patent citations and the relative number of patent claims are selected as the measurement indicators of technology benefit gap [19].

\subsection{Evaluation method}

In this paper, entropy method and TOPSIS method are used to quantitatively evaluate the ability of autonomous control. Entropy method is an objective weighting method, which can determine the index weight according to the information provided by the observation value of each index. The improved TOPSIS method is a common decision-making method suitable for multi-objective decision-making [20]. The specific calculation steps are as follows:

(1) Index weight calculation

1) Data standardization. There is a big difference between the measurement unit and the order of magnitude of the original data, and each index in the evaluation index system of high-end equipment manufacturing industry's independent controllable ability has a different direction of action on the evaluation objectives, so it is impossible to directly compare with each other. In order to ensure the accuracy of the evaluation results, the original data should be standardized first. The original data are processed by dimensionless quantization:

$$
x_{i j}^{\prime}=\frac{x_{i j}-x_{\min }}{x_{\max }-x_{\min }}
$$

In Formula(1) : $x_{i j}^{\prime}$ is the index value after standardization; $x_{i j}$ is the original value of index $\mathrm{j}$ of the $\mathrm{i}$ object; $x_{\min }$ is the minimum value of the index; $x_{\max }$ is the maximum value of the index.

(2) Weight calculation

2) Calculate the specific gravity $p_{i j}$ of $x_{i j}$ :

$$
p_{i j}=\frac{x_{i j}}{\sum_{i=1}^{n} x_{i j}}(\mathrm{i}=1,2, \ldots \mathrm{m} ; \mathrm{j}=1,2 \ldots \mathrm{n})
$$

3) Calculate the entropy $e_{i}$ of index i:

$$
e_{i}=-\frac{1}{\ln n \sum_{j=1}^{n}\left(p_{i j} \ln p_{i j}\right)}
$$

4) Calculate the weight $w_{i}$ of index i: 


$$
w_{i}=\frac{1-e_{j}}{\sum_{j=1}^{m}\left(1-e_{j}\right)}
$$

(2) Calculation of self control ability

1) Calculation of weighted normalized matrix:

$$
\begin{gathered}
Z=\left(Z_{i j}\right)_{m \times n} \\
\text { among } Z_{i j}=w_{j} \times x_{i j}
\end{gathered}
$$

2) The positive and negative ideal solutions of the weighted normalized matrix are calculated:

$$
\begin{aligned}
& Z_{j}^{+}=\left\{\max Z_{i j} \mid i=1,2,3 \mathrm{~L}, n\right\} \\
& Z_{j}^{-}=\left\{\min Z_{i j} \mid i=1,2,3 \mathrm{~L}, n\right\}
\end{aligned}
$$

3) Euclid distance between the solutions to positive and negative ideal solutions is calculated:

$$
\begin{gathered}
d_{i}^{+}=\sqrt{\sum_{j=1}^{n}\left(Z_{i j}-Z_{j}^{+}\right)^{2}} \\
d_{i}^{-}=\sqrt{\sum_{j=1}^{n}\left(Z_{i j}-Z_{j}^{-}\right)^{2}}
\end{gathered}
$$

4) Calculate the closeness between the i evaluation object and the optimal scheme:

$$
C_{i}=\frac{d_{i}^{+}}{\left(d_{i}^{+}+d_{i}^{-}\right)}
$$

5) Evaluation index of high end equipment manufacturing industry's independent controllable ability:

$$
Q_{i}=\frac{1}{C_{i}}
$$

\section{Empirical research}

\subsection{Data sources and scope}

This paper takes the marine equipment manufacturing industry in the high-end equipment manufacturing industry as an example for empirical research. The retrieval period is from 2000 to 2019 . In order to ensure the reliability and integrity of the data, after the retrieval is 
completed, the impurity data is cleaned up through manual screening. Search keywords mainly include: Tubular platform, gravity platform, tower platform, bottom platform, jackup platform, semi-submersible platform, drilling ship, jack-up production platform, tension leg production platform, single cylinder production platform, semi-submersible production platform, floating production, storage and unloading platform, drilling production, storage and loading vessel.

\subsection{Measurement of autonomous and controllable ability}

Using the patent data collected in the global database, according to the steps and methods of index weight calculation in Section 2.3, the index weight values at all levels are obtained. The specific weight calculation results are shown in Table 1

Table 1. Weight of each level evaluation index of independent and controllable ability of marine equipment manufacturing industry.

\begin{tabular}{|c|c|c|c|c|c|}
\hline $\begin{array}{l}\text { First level } \\
\text { indicators }\end{array}$ & weight & $\begin{array}{l}\text { Second level } \\
\text { indicators }\end{array}$ & weight & Third level indicators & weight \\
\hline \multirow{7}{*}{ Autonomy } & \multirow{7}{*}{0.619} & \multirow{3}{*}{ innovation ability } & \multirow{3}{*}{0.435} & $\begin{array}{c}\text { Number of new invention patent } \\
\text { applications }\end{array}$ & 0.333 \\
\hline & & & & Number of new invention patents granted & 0.291 \\
\hline & & & & Number of new patents cited & 0.376 \\
\hline & & \multirow{4}{*}{$\begin{array}{l}\text { competitive } \\
\text { power }\end{array}$} & \multirow{4}{*}{0.565} & Total number of patents granted & 0.272 \\
\hline & & & & Total number of invention patents granted & 0.251 \\
\hline & & & & $\begin{array}{c}\text { Total number of high quality invention } \\
\text { patents }\end{array}$ & 0.221 \\
\hline & & & & Total number of citations & 0.256 \\
\hline \multirow{8}{*}{$\begin{array}{c}\text { Controllabili } \\
\text { ty }\end{array}$} & \multirow{8}{*}{0.381} & \multirow{3}{*}{ Scale gap } & \multirow{3}{*}{0.321} & Relative patent applications & 0.322 \\
\hline & & & & Relative patent authorization rate & 0.252 \\
\hline & & & & Relative patent growth & 0.426 \\
\hline & & \multirow{3}{*}{ Quality gap } & \multirow{3}{*}{0.413} & Number of relative patent citations & 0.252 \\
\hline & & & & $\begin{array}{l}\text { Relative number of patents of the same } \\
\text { family }\end{array}$ & 0.410 \\
\hline & & & & Relative international patent application & 0.338 \\
\hline & & \multirow{2}{*}{ Benefit gap } & \multirow{2}{*}{0.266} & Relative patent citation quantity & 0.488 \\
\hline & & & & Relative number of patent claims & 0.512 \\
\hline
\end{tabular}

It can be seen from Figure 1 that the independent controllable ability of China's marine equipment industry has not changed much for a long time before 2010. Since 2010, the independent controllable ability of China's marine equipment manufacturing industry has been significantly improved, indicating that the national medium and long term technology development plan (2006-2020) in 2006 listed large-scale marine engineering technology and equipment as the eight key breakthrough areas A series of policies, such as the priority theme of large manufacturing industry, have played a great role in promoting the development of China's marine equipment manufacturing industry. 


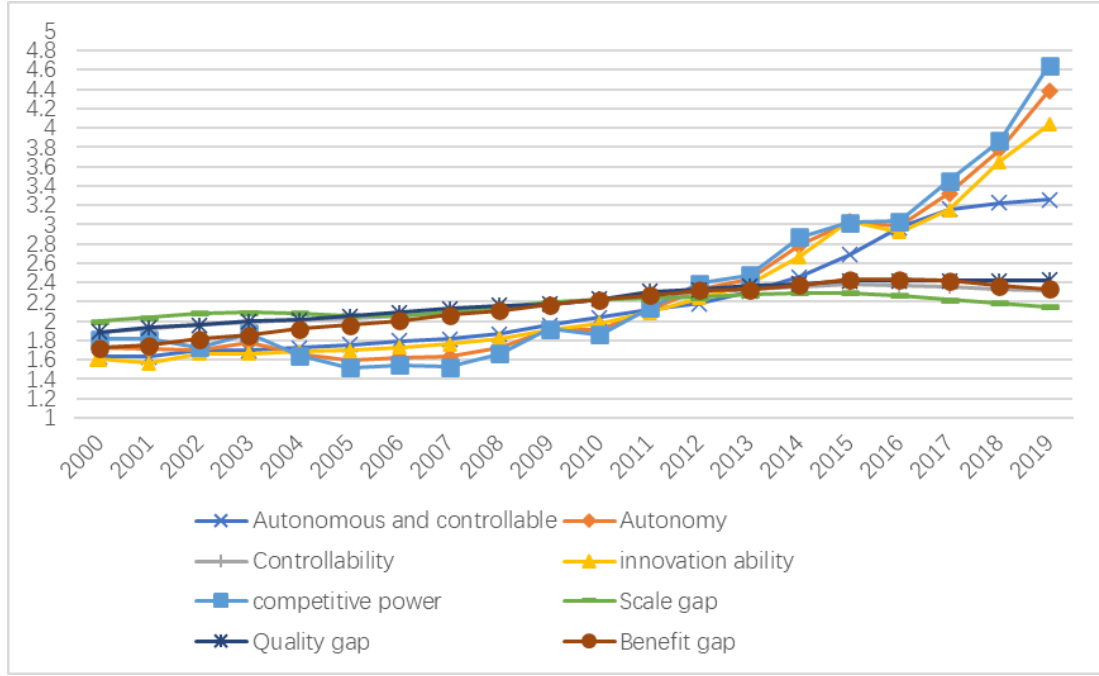

Fig. 1. Evaluation and comprehensive evaluation trend of independent and controllable ability of China's marine equipment manufacturing industry.

\section{Conclusion}

In this paper, uses the patent data of global patent database from 2000 to 2019 as the sample to measure the independent controllable ability of China's marine equipment manufacturing industry. The research results show that the measurement results of each dimension of independent controllable are consistent with the facts of industrial development, indicating the scientificity of the established index system and the applicability of the calculation method. This study provides a scientific method to measure the independent controllable ability of China's high-end equipment manufacturing industry, and provides a reference for improving the independent controllable ability of China's highend equipment manufacturing industry.

\section{References}

1. Wang Fansheng, Mao Jianqi. Research on China's industrial technology security based on global technology chain [J]. Economic and management research, 2009(10):43-50.

2. Sun Ruihua, Liu Guangsheng. Research on the construction of industrial safety evaluation index system $[\mathrm{J}]$. Scientific and technological progress and countermeasures, 2006(05):138-140.

3. Jingyuqin. Research on the index system of industrial safety evaluation [J]. Economist, 2006(02):70-76.

4. Li Yan. The construction and Empirical Study of manufacturing industry safety evaluation system under the innovation ecosystem [J]. China Science and Technology Forum, 2018(09):22-30.

5. Su Yan. Building an independent and controllable advanced manufacturing system $[\mathrm{N}]$. Xinhua Daily, 2018-08-06.

6. Hensel N. Can Industry Consolidation Lead to Greater Efficiencies? Evidence from the U.S. Defense Industry[J]. Business Economics, 2010,45(3):187-203. 
7. Bellais R, Guichard R. DEFENSE INNOVATION, TECHNOLOGY TRANSFERS AND PUBLIC POLICY[J]. Defence and Peace Economics, 2006,17(3):273-286.

8. LAN Yuqing, Yu Dan. "Made in China 2025" and the construction of independent controllable system of military industry group [J]. China Science and technology information, 2015(18):94-95.

9. $\mathrm{Xu}$ Guofeng, Xu pengwen, Zou Hongxia. Application of domestic self controlled technology in office automation of military academies [J]. Journal of Sichuan Ordnance Engineering, 2014,35(03):130-132.

10. Xu Xiping, Xiao Zhenhong. Research on self control of national defense science and technology industry based on knowledge flow [J]. Scientific management research,2017,35(06):57-60.

11. Wang Liheng, Zhou Zhicheng, Wang kunsheng, et al. Study on evaluation method of industrial system maturity [J]. China Engineering Science,2020,22(02):91-97.

12. Li menggang. Theoretical research on industrial security [J]. Management modernization,2006(03):49-52.

13. He Weida, Liu Yaning, Zhang Kai. Safety assessment of China's equipment manufacturing industry based on principal component analysis [J] Management informatization in China, 2013,16(10):31-34.

14. Zhou Mi. Summary of technology gap theory [J]. Comparison of economic and social systems, 2009(03):186-191.

15. Cao Ping, Zhang Jian, Xiong Yan. An Empirical Study on the influencing factors of high tech industry security [J]. Management review, 2017,29(12):50-61.

16. Deng Xiuquan, Wu Min, Shangguan Chunxia, Wang Linhua. Investigation and analysis of core competence elements -- Based on China journal full text database [J] Scientific research management, 2003(02):109-115.

17. Griliches Z. Issues in Assessing the Contribution of Research and Development to Productivity Growth[J]. NBER Chapters, 1998.

18. Yang Zhongkai, sun Yutao. Comparison of national technological strength indicators based on patent citation $[\mathrm{J}]$. Science of science and technology management, 2005(10):11-14.

19. Yang Wu, Yang Dafei, Ju Yun. Research on industrial technology security measurement under the framework of technology gap theory -- Taking $5 \mathrm{~g}$ mobile communication industry as an example $[\mathrm{J}]$. Scientific and technological progress and countermeasures,2019,36(08):60-67.

20. Hu Yonghong. Improvement of TOPSIS method in comprehensive evaluation [J]. Practice and understanding 